\title{
MOIRÉ INTEFEROMETRY APPLIED TO PLANT ARCHITECTURAL STUDIES \\ MOIRÉ INTERFEROMÉTRICO APLICADO AO ESTUDO DA ARQUITETURA DE \\ PLANTAS
}

\author{
DANIEL ALBIERO ${ }^{1}$ \\ ROBERTO T. ATARASSI ${ }^{2}$ \\ ANTONIO JOSÉ DA SILVA MACIEL ${ }^{1}$ \\ INÁCIO M. DAL FABBRO ${ }^{1}$ \\ SILVESTRE RODRIGUES ${ }^{1}$ \\ ANTONIO C. L. LINO ${ }^{3}$
}

\section{ABSTRACT}

Plant architecture research subjects are of significant importance to genetics, photosynthesis, transpiration, crop-machine mechanical relationship, etc. In this sense, this research work had been carried in developing a new technique to generate the three dimensional view of plant shape. In this work the plant architecture determination will be carried out by means of a phase shift moiré method. The importance of the proposed method is based on the application of a sequence of four grids out of phase by an angle of $\pi / 2$ radians one from each other. A digital camera was employed to capture the moiré patterns, which will generate the image to be processed. The procedure of image analysis involved softwares as Microsoft Powerpoint, Coreldraw and Idrisi. The use of a highly continuous sinusoidal grid, of a collimated light beam, of a higher resolution Charge Coupled Device Camera, as well as the superposition of image discontinuities during the unwrapping procedure included in the phase shifting method, avoided noise occurrence satisfactorily, improving image quality. The conception of tests leading to height determination to generate a topographic description of a plant model was conceived based on optical moiré techniques. Obtained results reveal a great potential of the proposed method in determining plant architecture with high precision, at low cost and being not time demanding.

Keywords: Moiré; Interferometry, Plant Architecture.

\footnotetext{
${ }^{1}$ Agriculture Engineering College, State University of Campinas, University city Zeferino Vaz, Campinas, Brazil; e-mail of corresponding author: daniel.albiero@agr.unicamp.br

${ }^{2}$ Agriculture Collage Luiz de Queiroz, State University of São Paulo, Campus Piracicaba, Piracicaba, Brazil;

${ }^{3}$ Agriculture Institute of Campinas, Unit Jundiaí, Jundiaí, Brazil
} 


\section{RESUMO}

A arquitetura das plantas é muito importante para estudos de genética, fotossíntese evapotranspiração, e relações máquina/plantas. Esta pesquisa teve o objetivo de desenvolver um novo método para gerar uma imagem tridimensional das plantas. Esta nova técnica pretende determinar a arquitetura de plantas através do método de moiré "phase shift". A inovação está na utilização de grades defasadas por um ângulo de $\pi / 2$ radianos entre elas. Uma câmera digital foi utilizada para capturar os padrões moiré, que gerará as imagens a serem processadas. O procedimento para a análise das imagens envolvem softwares como o Microsoft Powerpoint, Coreldraw and Idrisi. O uso de uma grade sinusoidas de grande definição e de luz colimadada, assim com uma câmera CCD de alta resolução, assim como a superposição da descontinuidade durante o procedimento de "desenpacotamento" evitaram a ocorrência de ruído satisfatoriamente, melhorando a qualidade das imagens. A determinação da altura gerou um mapa topográfico de um modelo de planta que foi baseado em técnicas de moiré optico. Os resultados obtidos revelaram grande potencial do novo método proposto para a determinação da arquitetura de plantas com alta precisão, a baixo custo e pouco dispêndio de tempo.

Palavras-Chaves: Moiré, Interferometria, Arquitetura de Plantas.

\section{INTRODUCTION}

Plant architecture is of significant importance in providing basic information for research on genetics, on photosynthesis, on plant transpiration, on plant-machine mechanical relationship, on farm machinery design, robotics, as well as on general agricultural operations. The recognition of a plant shape has been reported by several authors by means of diverse techniques. Manual techniques as mentioned by LANG (1993), VARLET - GRANCHER et al. (1993) is based on one by one leaf measurement which is very laborious and time demanding, which, indirectly support the necessity of developing optical techniques to improve plant architecture survey. A large number of algorithms based on image synthesis had been proposed, however plant objects present a complex geometry deserving millions of triangles for an adequate geometrical representation.

A mathematical simplification of plant structure assumes a random organs spatial distribution (NORMAN \& CAMPBELL 1989). The question is focused in not only obtaining the object geometrical representation but also to obtain the radiation relations among plant organs. These facts impose a limit in applying shading and filtering techniques as it is normally used in computer graphics (AIRES et al., 1993). Tridimensional object geometrical description can be achieved through optical photogrametry, optical telemetry, articulated arms, ultrasonic telemetry and magnetic digitizer (MOULIA \& SINOQUET, 1993). Recently, machine vision systems combined with artificial neural networks (ANN) have been widely used for improving conventional modelling techniques (CHO et al., 2002). Remote sensing techniques have been used to estimate various plant parameters, providing instantaneous quantitative information on agricultural crops being a nondestructive method.

This research work reports the development of a technique based on the moiré interferometry, identified as a variation of the Phase Shift Method. The name moiré has its origin in the French language, referring to wave like pattern. When screens of same mesh density are superposed, fringes are generated which move when its relative positions are displaced. $\mathrm{SCHI}-$ AMMARELLA, (1982) proposed the application of a moiré technique in testing diffraction grids, being also useful to magnify displacements as well as suitable as a photoelastic method.

The use of image processing could be an efficient way for helping to determine indicators that characterize the plant quality, being an analysis of the morphology of the plant features could be particularly useful (FOUCHER et al., 2004). Moiré methods present several advantages for shape survey of irregular as well as regular object geometries (LINO, 2002). 
Moiré methods include a large number of techniques as shadow moiré, projection moiré and others as reported by Meadows et al. and Takasaki (DEGRIECK et al., 2001). Projection moiré consists in positioning a pair of grids in front of a light source and by moving the reference grid the light beam amplitude is modulated by the distance between grids generating the fringes when the light reaches the object surface.

Projection moiré with phase shift is a high precision technique, consisting in shifting the camera grid phase against the projecting grid (DEGRIECK et al., 2001). LINO (2002) reports a successful application of a projection moiré technique in surveying plant organs shape. A digital projection moiré would employ a direct grid projection and superimposition onto the object surface by means of multimedia equipment after which it is captured and demodulated.

\section{THEORETICAL CONSIDERATIONS}

Projection moiré consists in positioning a pair of grids in front of a light source and by moving the reference grid the light beam amplitude is modulated by the distance betweengrids, generating the fringes when the light reaches the object surface. Projection moiré with phase shift is a high precision technique, consisting of shifting the camera grid phase against the projecting grid (DEGRIECK et al., 2001). A phase shift is generated by changing the distance between the object and the grid or by the translation of the grid on its own plane. A useful tool consists of generating a grid with varying gray level (DEGRIECK et al., 2001).

Grid modulation intensity is given:

$$
T(x)=\frac{1}{2}+\frac{1}{2} \sin \left(\frac{2 \pi x}{p}\right)
$$

where $T(x)$ the modulation and $p$ is the grid period in seconds. DEGRIECK et al. (2001) present the following equation for light intensity distribution in $(x, y, z)$ point considering a sinusoidal grid.

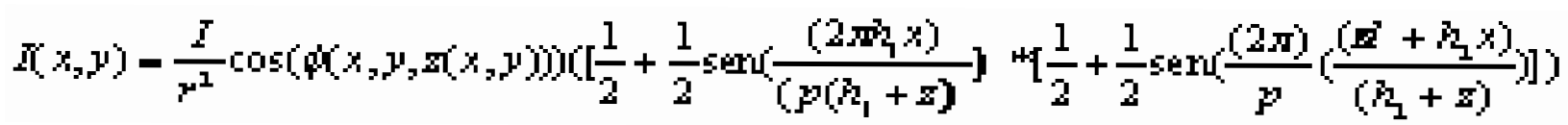

Where $I(x, y)$ is light intensity, $r$ is the distance between the light source and the surface being illuminated, $\phi$ is the angle between the incident light beam and the ${ }^{(2)}$ normal to the surface, $p$ is the reference grid period, $h_{1}$ is the distance between light source and the reverence grid and $h_{2}$ is the distance the observer and the reference grid.

QUAN et al. (2001) reports that system non-linearity and noise occurrence might generate edge errors due to surface discontinuity in relation to the plane. Three or four images with different and continuous grids and sinusoidaly spaced fringes were needed to obtain object surface and contour. For three-dimensional contour determination it is generally necessary four sinusoidal grids projected onto the object surface with fringes phase varying as $0, \pi / 2, \pi \mathrm{e}$ $3 \pi / 2$, (QUAN et al., 2001). Image light intensity distribution for these phases is: $\pi$

$$
\begin{array}{r}
I_{1}(x, y)=a(x, y)+b(x, y) \cos (\varphi(x, y) \\
I_{2}(x, y)=a(x, y)+b(x, y) \cos (\pi / 2+\varphi(x, y)
\end{array}
$$




$$
\begin{gathered}
I_{3}(x, y)=a(x, y)+b(x, y) \cos (\pi+\varphi(x, y) \\
I_{4}(x, y)=a(x, y)+b(x, y) \cos (3 \pi / 2+\varphi(x, y)
\end{gathered}
$$

Where $a(x, y)$ is the average ligth intensity, or background, $b(x, y)$ is the modulation intensity and $j(x, y)$ the phase to be determined. Phase can be obtained from the following equation:

$$
\varphi(x, y)=\arctan \left(\frac{I_{4}(x, y)-I_{2}(x, y)}{I_{1}(x, y)-I_{3}(x, y)}\right)
$$

Phase and height relation for triangulation was obtained through the following equation (Quan et al.., 2001):

$$
h(x, y)=\frac{L}{d} \overline{\mathbb{A}^{+}}=\frac{L}{d} \frac{\varphi_{\mathscr{D}}}{(2 \pi f)}=k \varphi_{D}
$$

Where $h(x, y)$ is'the for the height at the point $(x, y) L$ is the distance between the camera and the reference plane, $d$ is the distance between the camera and the projector, $\varphi C D$ is the phase, $f$ is the spatial frequency of the fringes projected onto the reference plane and $\mathrm{k}=\mathrm{L} /$ $(2 d \pi f)$ for the system configuration (Fig. 6b).

This fringe projection method allows object contour determination (QUAN et al., 2001). Uncertainties in phase-depth conversion can generate errors on the final measurement, which limits the application of that method for some cases. Digital camera distortion also generates significant errors (LIU et al., 2003). By using a unique sinusoidal grid instead of a full grid and by translating only $1 / 4$ of the wave period keeps the light intensity variation tendency in the same sense, minimizing the errors due to surface discontinuity in relation to the reference plane (ALBIERO et al., 2003). The objectives of this research work can be identified as to improve the phase shift method applied to plant architectural studies as reported by ALBIERO et al. , (2003).

\section{MATERIAL AND METHODS}

The experimental phase of this research work was developed in the Laboratory of Physical Properties of Biological Materials at the Faculty of Agricultural Engineering, Unicamp,
Campinas, SP, Brazil. The object under study consisted of plastic model of an ornamental plant, which was painted with opaque white painting to avoid reflexion of incident light and further positioned before a wooden background as shown in Fig. 1. Four sinusoidal grids were generated by the Coreldraw 11 software and transformed into a slide sequence by the Microsoft Powerpoint software. Each grid was $p / 2$ radians out of phase in the sequence. Normally, phase shifting methods project a complete wave sequence onto the object, but ALBIERO et al. (2003) affirm that only $1 / 4$ of the complete wave should be projected to avoid errors on plant discontinuity, in this case only $1 / 4$ of a complete wave is being project as an innovative technique.

Such a procedure allows to obtain the topography of the object eliminating the fringes unwrapping step because only one fringe is being employed. Discontinuity of leafs borders indicate non real unwrapping. As stated by QUAN et al. (2001), moiré fringes unwraping can be understood as the light intensities separation, after the relative pixel position calculation as related to light intensities. These phases are wrapped, i.e., "packed" on a bidimensional plane, which after the calculation is represented on a three dimensional space. Due to leaves border discontinuity, singularities type errors are generated due division by zero. 
These errors are considered above the adequate limit to employ typical software of processing of fringe moiré, normally employed by traditional techniques.

The Grids illustrated by Figure 2 were project in the object by a multimedia projector, Figure 1. A Sony DSC P50 model digital camera adjusted in black and white with 2 Mpixels was employed to capture the images. A total of two sets of pictures were taken, being 5 photos each. In the first set the object was positioned before the background and in the second set only background was used. The five picture of each set employed the four sinusoidal grids, being $p / 2$ radians sequentially out of phase as it has been explained before, and one photo taken without grid, i.e. only white light. The 32.11 Idrisi software was employed to limit the object image by the leaves areas only, eliminating remaining parts as shown Figure 3.

Figure 4 illustrates the procedure to eliminate the shade projected onto the background, it was used background painted with the opaque colour and it was taken the picture, after this picture the plant model it was positioned forward the background an it was taken another picture. With these pictures was possible to use the software Idrizi where it was done the processing of the images with $t$ a maximum function pixel to pixel, this function allows to choose the pixel of greater intensity between to images. As the shade value is next to zero the procedure induces the substitution of the shade directly by the background. An error is generated by considering shade areas of leafs as background.

Filters were then applied to eliminate noises identified as discrepant high light intensities, resulting in a spatially continuous light distribution. Such noises were generated by the low resolution of the multimedia projector as well as the low sensibility of the digital camera to low luminosity environment. It was employed a Gaussian filter with a 7 by 7 pixel mask available in the Idrisi software. Next filtration eliminated the background behind the object for the four projected phases. The next and fifth photo was taken without the grid, to generate a mask which separate the area of the object and attributing zero value to the background. This way, only the object topography was generated. Figure 5 shows the four images generated to obtain the object topography, being each one associated to grid phase. Phase and height relation for triangulation was obtained through EQN. 7 and 8 (QUAN et al., 2001).

To evaluate noise generated for the setup. Grids were projected by means of multimedia projector connected to a Computer and the photos captured by P52 Sony digital camera with 2 Mpixels of resolution. The divergent light beam from the multimedia projector was collimated by means of Bauch Lomb collimating set with 550 $\mathrm{mm}$ focal distance. All angles were measured by means of a goniometer with 0.5 degrees of precision. Shade projections from one leave to other were avoided by setting the plant object in a convenient position.

All pictures were expressed in JPEG format followed by a BMP gray levels format, converted by means of the Gimp software, defining the gray level zero as dark colour and 255 as white colour. A total number of five pictures, being four pictures for the grids and one picture for white light with no grid were taken. Images were processed in 32.11 IDRISI software. The images were initially cut, obtaining the plant image without background, following by a masking procedure. In that procedure the plant image was multiplied by a binary image obtained from the white light projection picture, defined as zero value for regions of no interest and 1 value for the plant. Such an operation had the objective of reducing the data amount to be processed. Figure 7 shows the generated binary mask.

The relationship between phase and shape is shown on Figure. 6b. Points $P$ and $E$ represents the outgoing projector pupil and of the respectively. If the distance between the sensor and the reference plane is large as compared with the space between projected grids, phase and height will keep a certain relationship, as in the triangulation method (QUAN et al., 2001) and shown by Eqn (8).

$$
h(x, y)=\frac{L}{d} \overline{A^{\prime}}=\frac{L}{d} \frac{\varphi_{\mathscr{D}}}{(2 \pi f)}=k \varphi_{D}
$$

where $L$ stands for the distance between the sensor and the reference plane in $\mathrm{mm}, d$ is the distance between the sensor and the projector in $\mathrm{mm}, f$ is the spatial frequency of the fringe 
projected onto the reference plane in fringe $/ \mathrm{mm}$, $\mathrm{k}=(\mathrm{L} /(2 \mathrm{dpf})$ is the optical system configuration, jCD is the phase containing information about the height and $h(x, y)$ is the point hight in $\mathrm{mm}$. The light source origin was taken as the collimating lenses pupil. The above described parameters had the following numerical values: $L=250$ $\mathrm{mm}, \mathrm{d}=1000 \mathrm{~mm}, \mathrm{f}=0.1$ fringe $/ \mathrm{mm}, \mathrm{k}=6,366$ $\mathrm{mm} /$ fringe.

\section{RESULTS AND DISCUSSION}

Figure 8 illustrates object height generated from the obtained data. By observing object height range one can note discrepant figures as negative values as well as values larger than $1 \mathrm{~m}$ which are not compatible with object width which is $0.5 \mathrm{~m}$. Such discrepancies can be attributed to noise ocurrence, mainly at leafs borders magnifying the problem after calculation procedure. This problem is particularly important when discontinuity between bordes are considered which generated noises on all the region next to error ocurrence. In other words, pixels next to pixels with singularities tends to exhibit distortions, which ocurrs because the light intensity phase at leave borders varies from the extreme positive values to extreme negative values in a zero tending space at unwrapping moment. Equation 7 indicates division by zero in that situation, however, the proposed phase translation technique circumvents such inconvenience because the wrapping step is not carried out, i.e., the whole light intensity modulation sinusoidal is not employed, but only $p / 2$, as presented on Figure 2. That wave range covers the whole object under study, not allowing border discontinuities during unwrapping procedure. In case of not adequate setup adoption, discrepant data is generated, noticing that object image height values are in close agreement with real values. However, these discrepant data do not tend to infinit which reinforces the efficience of the proposed method. Figure 9 shows the object image topography after eliminating negative values as well values higher than $0.9 \mathrm{~m}$, that is near to height topography range of the plant. In future works errors during data generation should be minimized. Also trials with real vegetable including leaf area will take place.

The proposed setup modifications as presented on Figure 6 together with the plant binary mask generation it was possible to eliminate discrepant data as exhibited on Figure. 8 and Figure 9, because collimated light provides parallel beam to the plant object, avoiding light interference as generated by the multimedia projector in which the light intensity varies in relation to the light source lenses, generating errors at the light phase calculation. The application of a goniometer allowed the exact angle used in calculating the parameters presented by Equation 8.

Figure 10 shows the plant phase map, which defines the integration of height information draw from the four images generated by the fringes projections. Figure 11 shows the topographic map generated by the triangulation method.

It should be noted that the scale from Figure 10 refers to phase angles from a sinusoidal wave, which means that abrupt white colour changing to dark colour is due to sine function tendency in exhibiting negative and positive derivatives. It should be also noted that zero phase value reefers to the inflection curve point in relation to the reference plane. Figure 11 shows that the plant contour lines do not exhibit similar abrupt changes because the triangulation method generates positive height values and for phase positive and negative values. In that same figure the zero height value is attributed to the reference plane, positioned at the plant baricenter. The coordinate orientation follows the multimedia orientation, which explains the ramp effect observed on the images. As stated before, shade projection from one leave to the others was avoid as recommended by ALBIERO et al. (2003).

Figure11 clearly indicates that the proposed technique generated results compatible with plant real dimensions. Also the employment of digital cameras with resolution over $12 \mathrm{Mpix}$ els will generate higher quality on light intensity beyond to avoid data losses.

\section{CONCLUSION}

In determining plant architecture the new technique contributed to the possibility of a system for superior plants recognition as well as its image digitalization. In considering the obtained results, it was possible to obtain a 
digital topography of a plant model. Obtained results demonstrate the potential of the method in generating data of plant architectural model topography in a easy and fast way. The discontinuity error of leaves border was eliminated, thus like fringe unwrapping step, but the simplified setup used generated much noise, that can to be note for the discrepant negative values as well as values larger, but with the setup precise was obtained results demonstrate the potential of the method in generating precise data of plant architectural. The use of collimated light beam as well as of a more precise angular and linear measure in terms of angles and distances reduced noise and errors occurences. Future work should consider real plants instead of plastic plant models applying coherent light beam, avoiding the application of opaque painting.

\section{REFERENCES}

AIRES, F; PREVOT L; MONESTIES, P. Crop structure and light microclimate: geometrical canopy modelling in radiation simulation studies. Institut National Recherche Agricole, Paris, n. 12, p. 159-173, 1993.

ALBIERO, D; ATARASSI, R T; CORNETA, M. E.; DAL FABBRO, I M; LINO,A C L; RODRIGUES, S; DAAMEN, M L J; GAZZOLA, J. (2003). Moiré interferometry applied to plant architectural studies. In: INTERNATIONAL CONGRESS ON INFORMATION TECHNOLOGY IN AGRICULTURE, FOOD ENVIRONMENT - ITAFE, 1, 2003, Izmir. Proceedings... Izmir : Ege University, 2003. v. 1. p. 612-617.

CHO, S I; LEE, D S; JEONG, J Y. Weed-plant discrimination by machine vision and artificial neural network. Biosystems Engineering, Elsevier, v. 83 n. 3, p. 275-280, 2002.

DEGRIECK J; VAN PAEPEGEN W; BOONE, P. Application of digital phase-shift shadow moiré to micro deformation measurements of curved surfaces. Optics and Laser in Engineering, Elsevier, v. 43 n.2, p. 29-40, 2001.
FOUCHER P; REVOLLON P; VIGOUROUX, B; CHASSÉRIAUX, G. Morphological image analysis for the detection of water stress in potted forsythia. Biosystems Engineering, Elsevier, v. 86, n. 2, p. 131-139, 2004.

LANG, A. R. G. Crop structure and light microclimate: cauchi's theorems and estimation of surface areas of leaves, needles and branches. Institut National Recherche Agricole, Paris, n.14, p.175-182, 1993.

LINO, A C L. Moiré optical technique to application in studies of irregular surfaces. 2002. Dissertation. (Masters degree in Agricultural Engineering) Faculdade de Engenharia Agrícola da Universidade Estadual de Campinas, Brasil.

LIU H; SU W H; REICHARD, K; YIN, S. Calibration based phase-shifting projected fringe perfilometry for accurate absolute $3 \mathrm{~d}$ surface profile measurement. Optics Communications, Elsevier, NY. v.49, n.2, p.65-80, 2003.

MOULIA B; SINOQUET, H. Crop structure and light microclimate: three-dimensional digiting systems for plant canopy geometrical structure: a review. Institut National Recherche Agricole, Paris, n. 15, p.183-193, 1993.

NORMAN J L; CAMPBELLI G. S. Canopy structure. Plant physiological ecology, London, n.33, n.1, p. 301-325, 1989.

QUAN C; HE, X Y; WANG, C F; TAY C J; SHANG, H. M Shape measurement of small objects using LCD fringe projection with phaseshifting. Optics Communications, Elsevier, v.189 n. 4 , p. 21-29, 2001.

SCHIAMMARELLA, C. A. The moiré method $-a$ review. Experimental Mechanics, Bethel, CT, v. 44 n.8, p. 418-433, 1982.

VARLET-GRANCHER C; BONHOMME R; SINOQUET H.Crop structure and light microclimate: characterization and application. Paris: Institut National Recherche Agricole - INRA, 1993. 518p. 


\section{List of figure Captions:}

Fig. 1. Experimental Arragement..

Fig. 2. Sinusoidal grid sequence out of phase by $\pi / 2$ radians.

Fig. 3. Example of original photo (a) and leaves area only (b).

Fig. 4. Image treatment to eliminate projected shade areas, being (c) images without shade as a result of the maximum function between images with object (a) and (b) only the background.

Fig. 5. Images for each sinusoidal grid without background.

Fig. 6. (a) Precise Experimental arrangement; (b) optical lay out for fringes projections as viewed on Eqn (8); (E) CCD Camera: Charge Coupled Device Camera; $(P)$ multimedia projec- tor (D) point sight; I: distance between the sensor and the reference plane in $\mathrm{mm}$; $d$ is the distance between the sensor and the projector in $\mathrm{mm}$; height and $h(x, y)$ is the point height in $\mathrm{mm}$.

Fig. 7. Plant binary mask.

Fig. 8. Object topography generated by moiré phase shifting technique. Values are the height of model given in meters.

Fig. 9. Object topography of the object as generated by the moiré phase shifting technique after discarding negative values as well values higher than $0.9 \mathrm{~m}$.

Fig. 10. Phase map generated from the four images arc tangent. Scale indicates phase angle values given in radians.

Fig. 11. Plant topographic map generated by the triangulation method. Values are the height of plant model, scale is given in $\mathrm{mm}$.

\section{Figures}

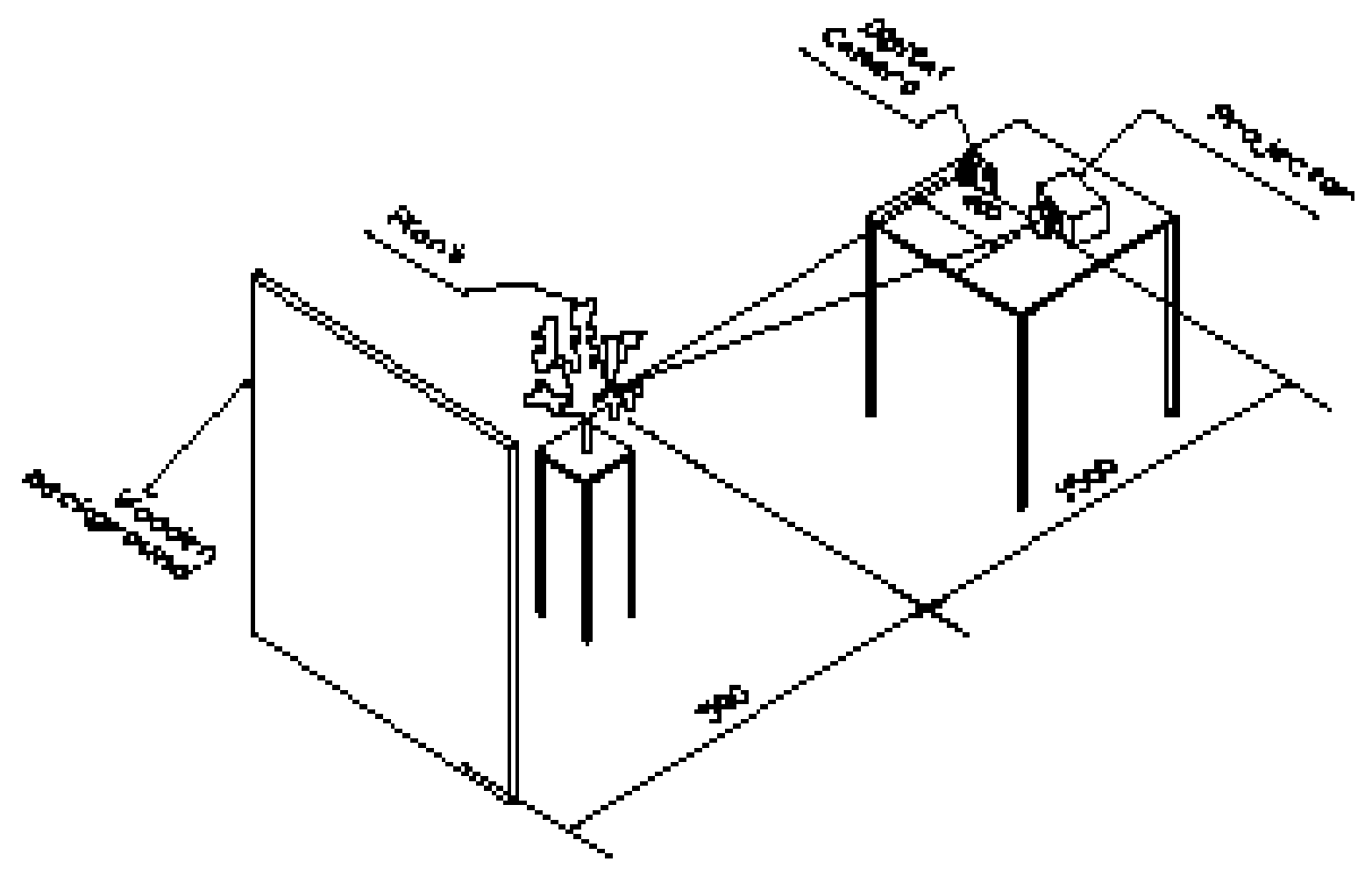

Figura. 1. Experimental Arragement 


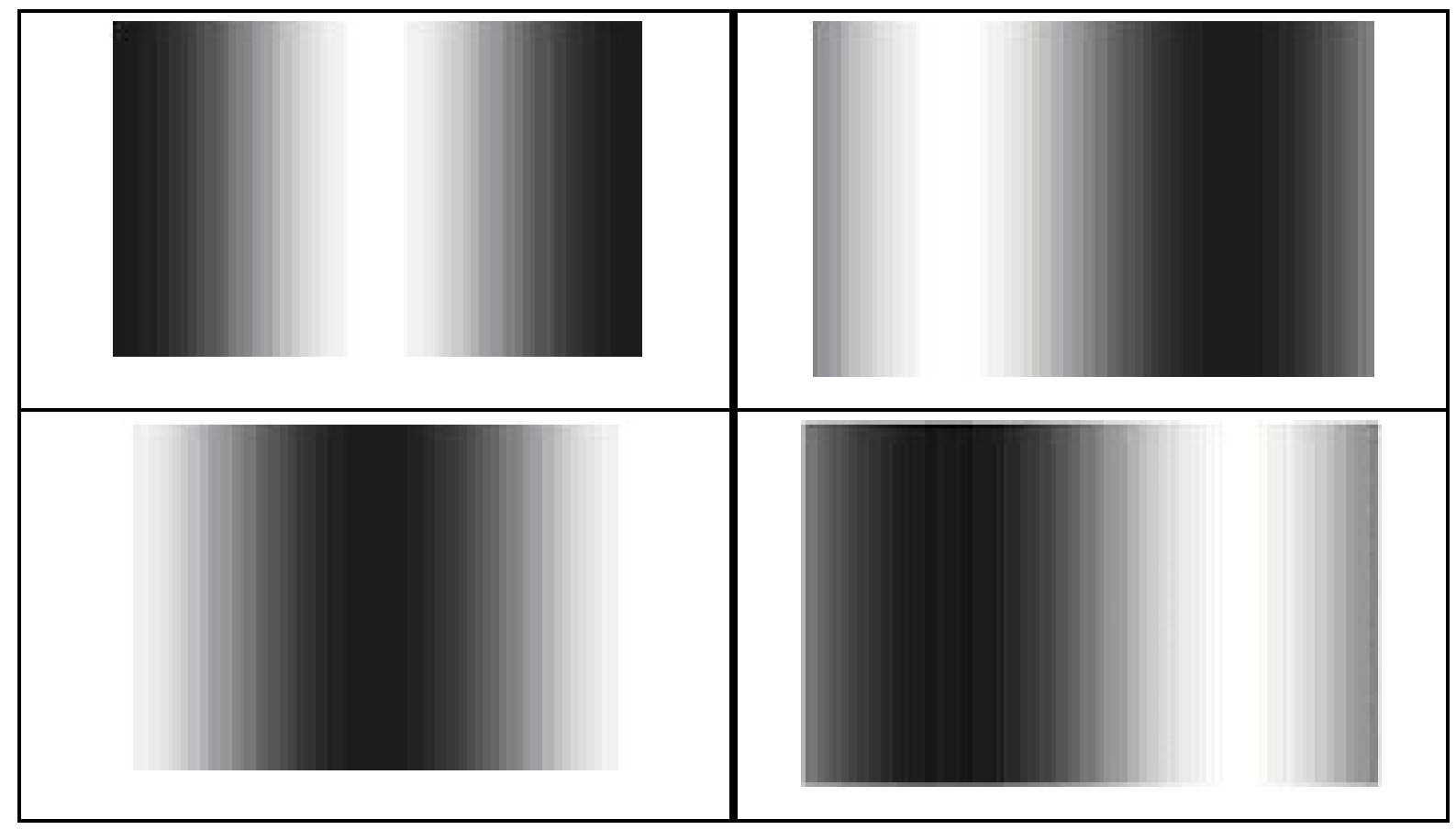

Figura 2. Sinusoidal grid sequence out of phase by $p / 2$ radians.
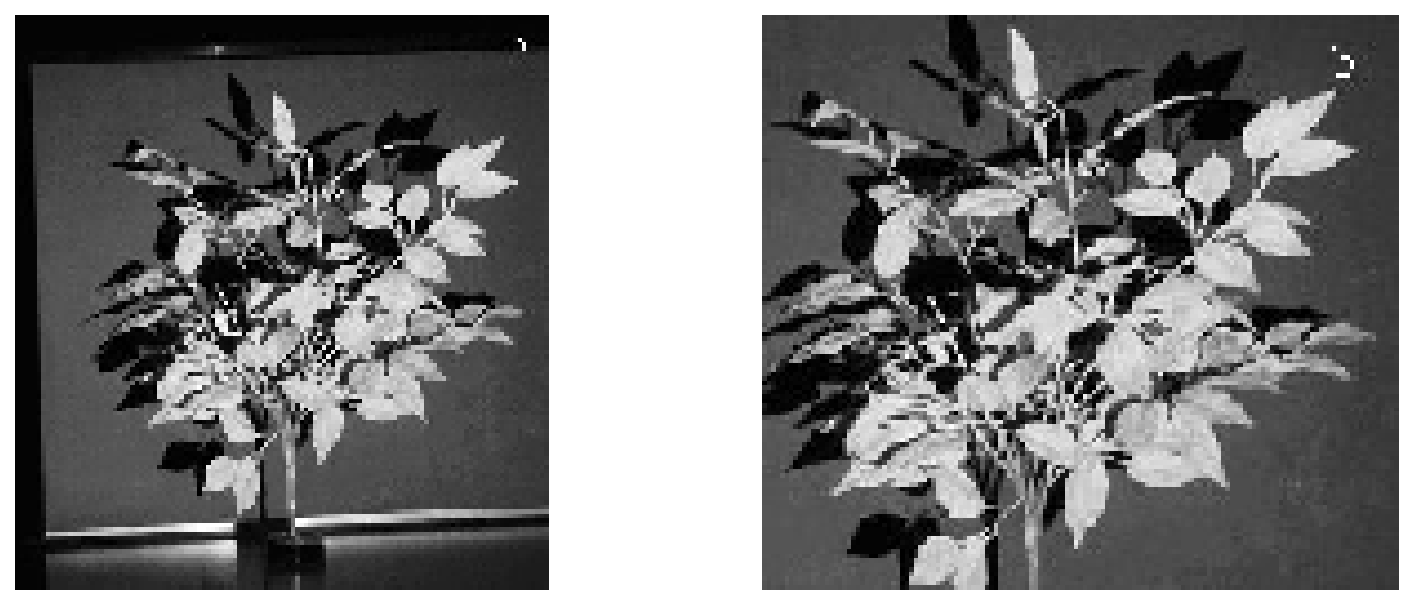

Figura. 3. Example of original photo (a) and leaves area only (b). 


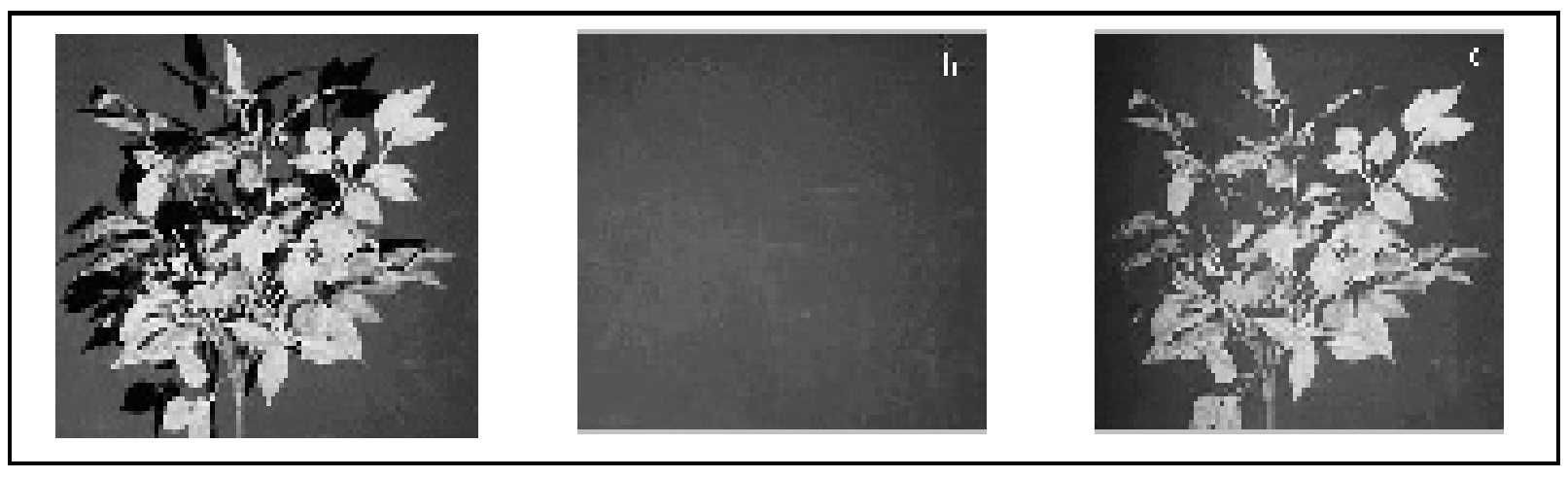

Figura. 4. Image treatment to eliminate projected shade areas, being (c) images without shade as a

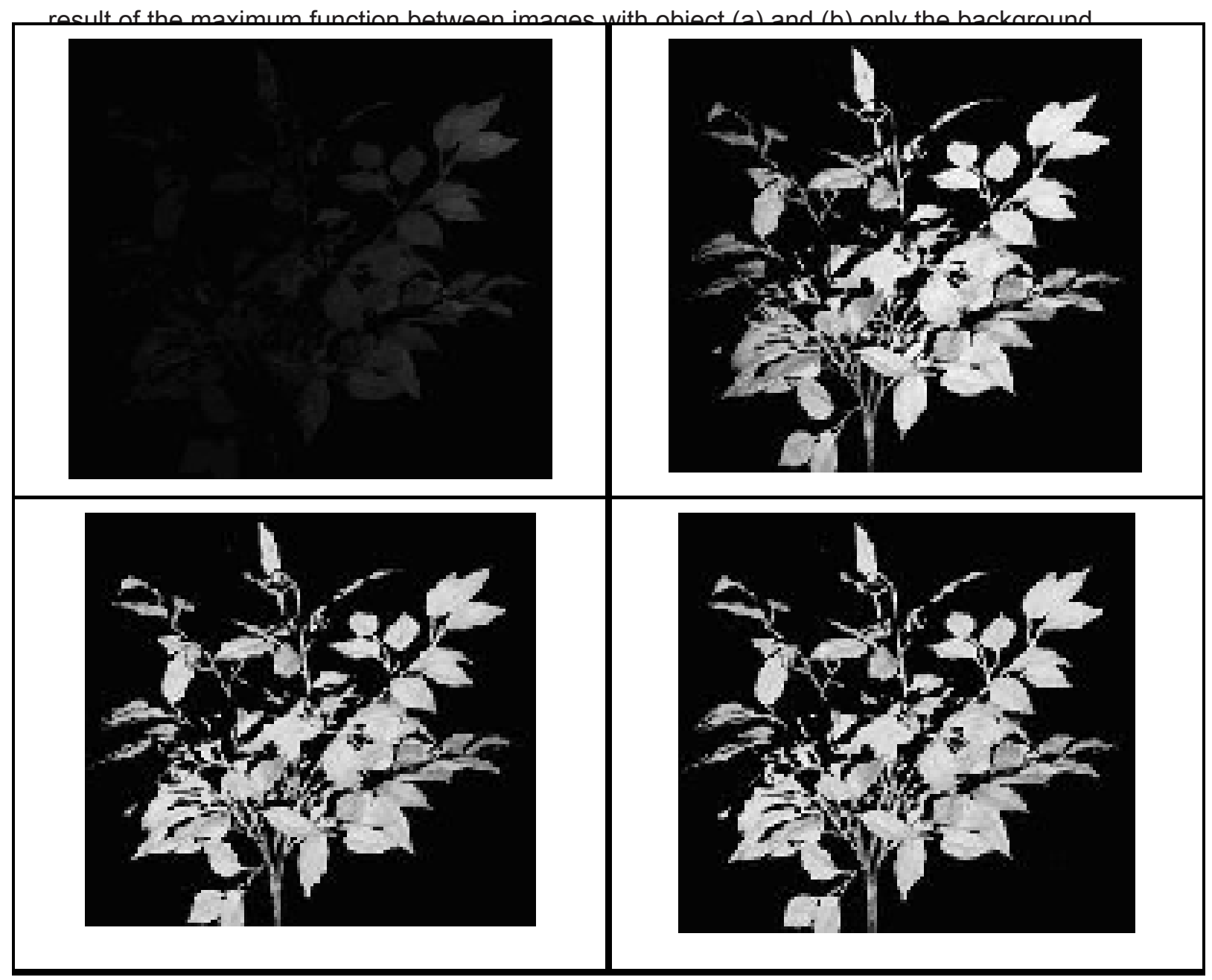

Figura 5. Images for each sinusoidal grid without background. 

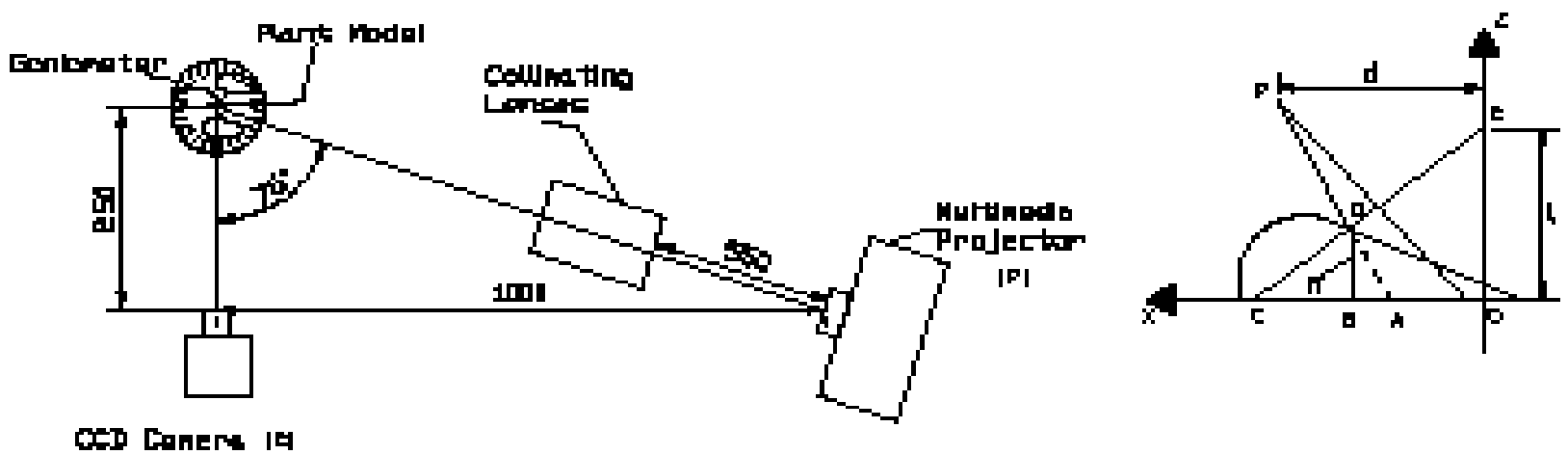

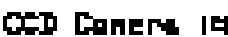

(a)

(b)

Figura 6. (a) Precise Experimental arrangement; (b) optical lay out for fringes projections as viewed on Eqn (8); (E) CCD Camera: Charge Coupled Device Camera;(P) multimedia projector; (D) point sight; I: distance between the sensor and the reference plane in $\mathrm{mm}$; $\mathrm{d}$ is the distance between the sensor and the projector in $\mathrm{mm}$; height and $\mathrm{h}(\mathrm{x}, \mathrm{y})$ is the point height in $\mathrm{mm}$.

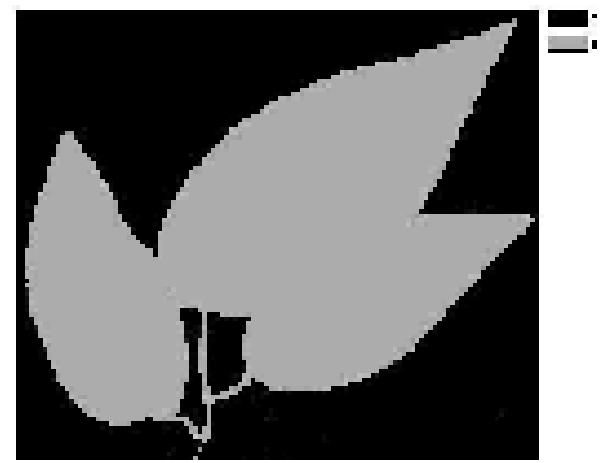

Figura 7. Plant binary mask. 

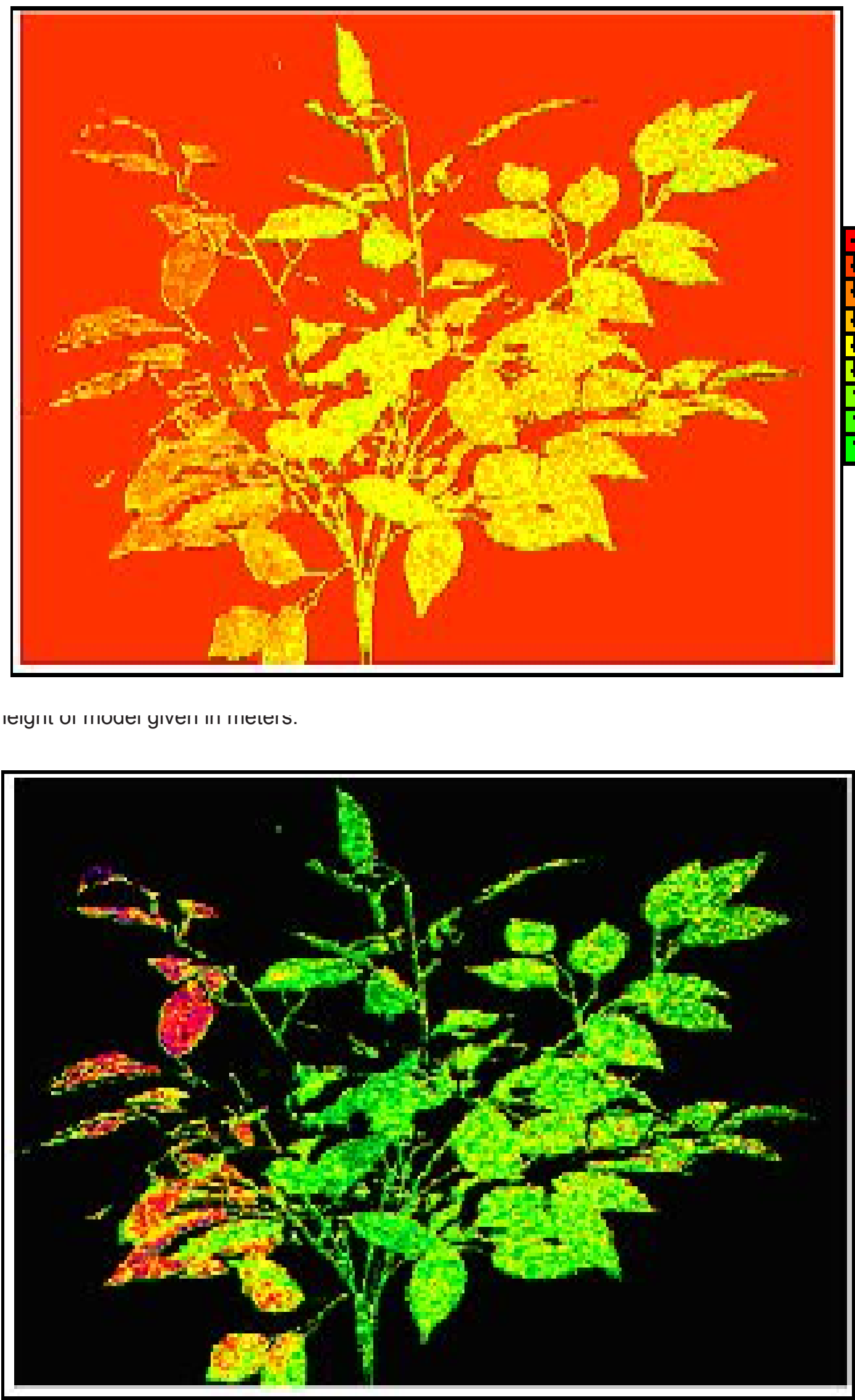

Figura 9. Object topography of the object as generated by the moiré phase shifting technique after discarding negative values as well values higher than $0.9 \mathrm{~m}$. 


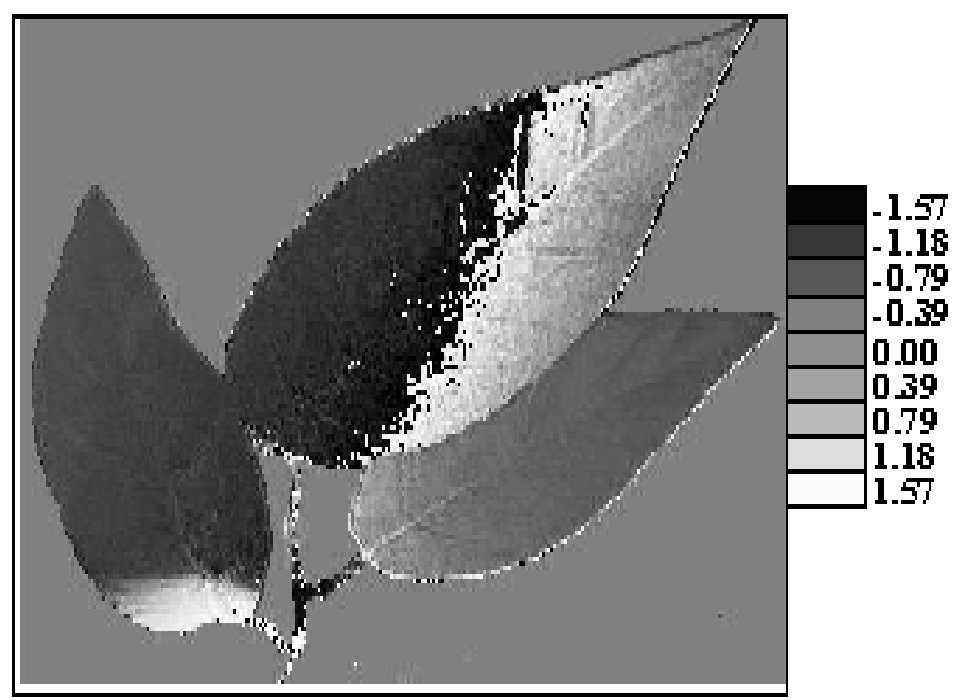

Figura 10. Phase map generated from the four images arc tangent. Scale indicates phase angle values given in radians.

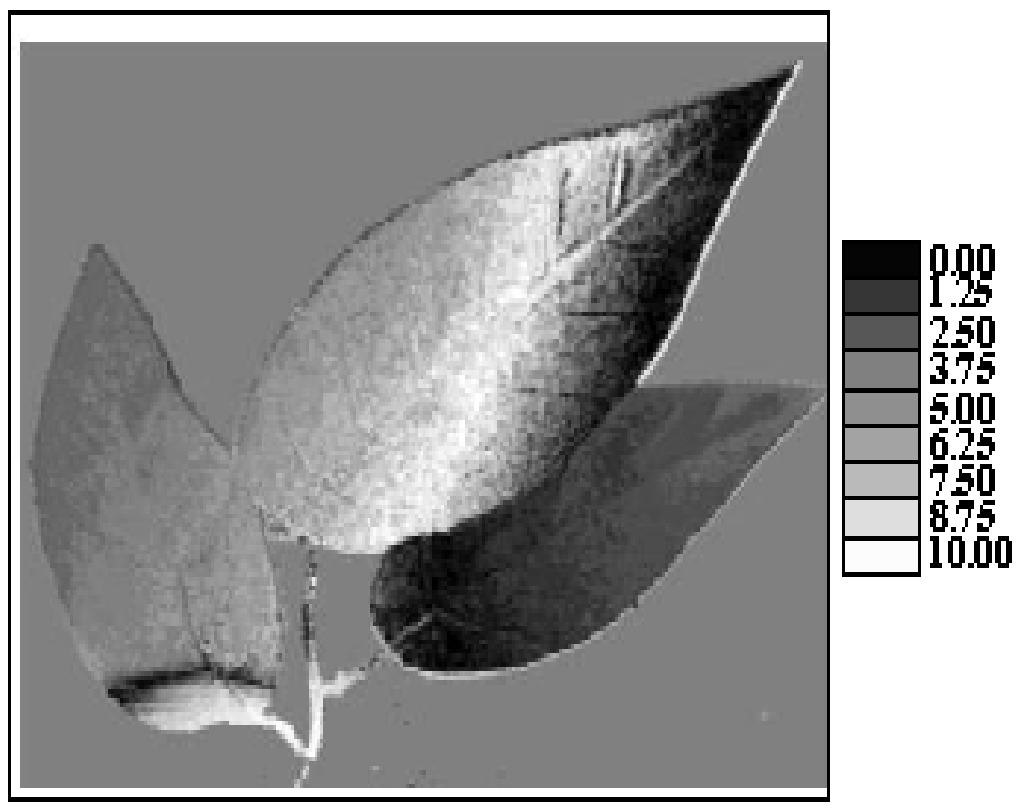

Figura 11. Plant topographic map generated by the triangulation method. Values are the height of plant model, scale is given in $\mathrm{mm}$. 